\title{
Transobturator mid urethral sling surgery for stress urinary incontinence: our experience
}

\author{
Ramesh Bettaiah, Reshu Saraogi, Chandana A. Reddy*
}

Department of Obstetrics and Gynecology, Dr Ramesh Hospital, Bangalore, India

Received: 03 September 2015

Revised: 03 September 2015

Accepted: 28 October 2015

\section{*Correspondence:}

Dr. Chandana A. Reddy,

E-mail: drchandana.a@gmail.com

Copyright: (c) the author(s), publisher and licensee Medip Academy. This is an open-access article distributed under the terms of the Creative Commons Attribution Non-Commercial License, which permits unrestricted non-commercial use, distribution, and reproduction in any medium, provided the original work is properly cited.

\begin{abstract}
Background: We retrospectively evaluated the cure \& improvement rate and complications incidence following transobturator approach of mid urethral sling surgery (MUS) for stress urinary incontinence (SUI).

Methods: Of the total 52 patients who underwent transobturator approach of midurethral sling surgery for stress urinary incontinence at Dr. Ramesh Hospital, Bangalore, India, between January 2006 - December 2009 , 48 women were available for clinical follow-up investigation. At follow-up, all 48 patients underwent a cough test, a pad test, and sonographic postvoid residual volume measurement. Women rated their subjective continence status (continent, slightly incontinent, incontinent). Objective cure was defined as a pad weight $0-1 \mathrm{~g}$ and a negative cough test.

Results: The minimum and median follow-up was 12 months \& 24 months respectively. Subjectively, $93.75 \%$ of the patients rated themselves as continent, $2.08 \%$ as slightly incontinent, and $4.16 \%$ as severely incontinent. The objective cure rate was $93.75 \%$. The surgery failed in 3 patients $(6.25 \%)$. 2 patients $(4.16 \%)$ underwent repeat surgery. There was one case $(2.08 \%)$ of vaginal erosion of mesh which required excision of the exposed part and one case $(2.08 \%)$ of urinary retention requiring incision of the mesh at the center.

Conclusions: Transobturator approach of mid urethral sling surgery is a safe, effective and minimally invasive procedure for SUI with a very low rate of complications.
\end{abstract}

Keywords: Stress urinary continence, Minimally invasive surgery, Transobturator tape, Prognosis, Complications

\section{INTRODUCTION}

Stress urinary incontinence (SUI) is estimated to affect between $15-60 \%$ of women. The negative impact of all types of urinary incontinence on female quality of life and, in particular, social, physical, psychological, occupational and sexual domains, have been extensively reported by several studies conducted in different populations, ${ }^{1,2}$ hence the need for proper evaluation and treatment of this condition.

In the last two decades, the history of pathogenesis and surgical treatment of SUI has been completely revolutionised. The integral theory of continence by
Petros and Ulmsten in 1995 underlined the essential role of the pubo-urethral ligaments in the mechanism of SUI, resulting in the introduction of trans vaginal tape (TVT), a minimally invasive and very efficacious operation. ${ }^{3}$ This first generation sling requiring blind retropubic needle passage was associated with a variety of intra and post-operative complications including bladder perforation, pain, voiding dysfunction, and de novo urge symptoms. Other rare but potentially serious injuries to the urethra, bowel or arteries and nerves in the retropubic space as well as mortalities attributed to either major vascular or bowel injury have also been reported. ${ }^{4}$ 
Few years later, on the basis of the equally plausible 'hammock hypothesis' by De Lancey, suggesting that the posterior position of the vagina provides a backboard against which increasing intra-abdominal forces compress the urethra, Delorme in 2001 and de Leval in 2003 conceived the transobturator approach; ouside -in and inside out respectively. ${ }^{5,6}$ The transobturator approach of mid-urethral sling, considered to be the second generation sling, was developed in an attempt to reduce the potential for complications associated with the retropubic access route inherent to the prior tape procedure. Since its introduction, the transobturator approach has increased in popularity because of the ease of the approach and the safety advantages inherent in avoiding the blind retropubic needle passage.

Subsequently, "mini-slings", the third generation sling was introduced. The "mini-slings" sling is secured to the obturator internus via a single vaginal incision, eliminating the need for incisions suprapubically or in the obturator fossa. Few studies conducted have shown comparable results with the second generation slings, however, studies with long term follow up are unavailable.

The search for the perfect treatment for SUI continues. Surgeons continue to look for the least invasive approach with optimal outcomes that also minimize the potential for adverse events preoperatively. Despite the variety of sling placement techniques, it must be emphasized that the concept of the midurethral sling has undergone minimal changes since its description by Ulmsten and Petros in $1995 .^{3}$ A mid-urethral sling (MUS) is considered to be the standard care for women with SUI and is attended with high short and intermediate success ${ }^{7}$. The aim of our study was to evaluate the outcomes and complication incidences with the transobturator approach of midurethral sling surgery (second generation) for female SUI.

\section{METHODS}

Between Jan 2006 and Dec 2009, 52 women with clinically demonstrable SUI underwent transobturator sling surgery at Dr. Ramesh Hospital, out of which only 48 were available for follow up in 2010 , as four patients could not be located (did not answer the phone after several calls). The minimum period of follow up was 12 months. A written informed consent was obtained from all patients. The recruited population was consecutive and therefore without selection bias.

All women who underwent surgery had predominant SUI symptoms, a positive cough stress test, and a bladder capacity >200 ml. A comprehensive preoperative evaluation including medical history, physical examination and urinalysis was performed. The diagnosis of SUI was made by clinically demonstrating SUI on cough test at a bladder volume of $200 \mathrm{ml}$ or symptomatic fullness (dorsal lithotomy \& standing position). Pelvic organ prolapse (POP) if present was reduced before the cough stress test. In our study, SUI was demonstrated in all patients who presented with the symptom. Studies have shown that a negative cough test effectively rules out most cases of stress incontinence. Urodynamic study was performed only on 6 patients with history suggestive of mixed SUI and all of them were found to have a predominant SUI component as studies have shown that urodynamic testing may not be cost effective if the probability of SUI is high ( $>80 \%$ ) and it may detect only $60 \%$ of uninhibited detrusor contractions. Women with vaginal support defects or previous gynecological surgery and mixed urinary incontinence (MUI) were included in the study whereas patients with previous failed incontinence surgery were excluded.

The different types of slings used are summarized in Table 1.

Four patients (one patient from the Monarc group, two from the Lotus group and one from the Gynecare TVTO) were not available for follow-up. Monarc (TOT outside-in approach) was performed in 2 patients who underwent surgery in early 2006. Thereafter, either the Lotus tape or the Gynecare TVT-O system was used. Seven patients underwent MUS surgery with Lotus tape (Indian) outside-in approach who could not afford Gynecare TVT-O system. In thirty nine patients, Gynecare TVT-O (inside-out) was used. All the surgeries were performed by the same surgeon (Dr. Ramesh) using the standard technique described for each type of sling. Patients were asked to cough at the end of the procedure to adjust the position of the sling whereas in cases carried out under general anesthesia, manual suprapubic pressure was applied. Cystoscopy was not performed in any patient after the procedure as it is not indicated in transobturator procedure and also as there was no suspicion of any bladder or urethral injury.

Table 1: The different types of slings used.

\begin{tabular}{|lll|}
\hline Type of sling & No. of patients & $\%$ \\
\hline Monarc & 2 & 4.16 \\
\hline Lotus & 7 & 14.57 \\
\hline $\begin{array}{l}\text { Gynecare TVT- } \\
\text { O system }\end{array}$ & 39 & 85.43 \\
\hline
\end{tabular}

At follow-up, all patients underwent a cough test and a pad test with an ultrasound controlled bladder volume of approximately $200 \mathrm{ml}$. Women assessed their subjective continence status using a simple questionnaire (continent, slightly incontinent, incontinent). Subjective cure (continent) was defined as no use of pads.

Success rate was defined as follows: Objective cure was defined as a negative cough stress test and a 1-h pad test giving a weight of less than $1 \mathrm{~g}$. Objective improvement was defined as a negative cough stress test and a 1-h pad test weight of 1- $5 \mathrm{~g}$. Failure was defined as a positive 
cough stress test and urine leakage more than $5 \mathrm{~g}$ in the 1 $\mathrm{h}$ pad test.

Quantitative data are presented in text as mean \pm SD. Qualitative data are presented as number and percentage.

\section{RESULTS}

Mean age of 48 patients was $48.16 \pm 9.38$ at surgery. Mean preoperative duration of incontinence was $10.8 \pm$ 8.08 months. Median follow-up was 24 months. Prior history of hysterectomy was reported in 5 patients (10.41 $\%)$.

Patient characteristics are listed in Table 2.

Table 2: Patient characteristics.

\begin{tabular}{|ll|}
\hline Patient characteristics \\
\hline $\begin{array}{l}\text { Mean Age in years } \\
\text { (range) }\end{array}$ & $48.16(30-70)$ \\
\hline Parity, median (range) & $2(0-4)$ \\
\hline BMI $\left(\mathrm{kg} / \mathrm{m}^{2}\right)$ & $23(21-29)$ \\
\hline Postmenopausal & $18(37.5 \%)$ \\
\hline $\begin{array}{l}\text { Previous } \\
\text { hysterectomy }\end{array}$ & $5(10.41 \%)$ \\
\hline
\end{tabular}

Data are expressed as median (range) or number (\%)

Cystocele repair was done in 3 patients (6.25\%) simultaneously. Rectocele repair was done in 2 patients $(4.16 \%)$ Cystocele and rectocele repair were done in another two patients $(4.16 \%)$. Concomitant vaginal hysterectomy was done in 5 patients $(10.41 \%)$ and Total Laparoscopic Hysterectomy (TLH) in 4 (8.33\%) patients. The surgical procedure performed is listed in Table 3.

Table 3: Surgical procedures performed.

\begin{tabular}{|lll|}
\hline Surgery & $\begin{array}{l}\text { No. of } \\
\text { patients }\end{array}$ & $\%$ \\
\hline Only MUS & 31 & 64.58 \\
\hline Anterior repair + MUS & 3 & 6.25 \\
\hline Posterior repair +MUS & 2 & 4.16 \\
\hline Ant \& post repair +MUS & 2 & 4.16 \\
\hline VH + MUS & 3 & 6.25 \\
\hline $\begin{array}{l}\text { VH + ant \& post repair + } \\
\text { MUS }\end{array}$ & 2 & 4.16 \\
\hline TLH + MUS & 2 & 4.16 \\
\hline $\begin{array}{l}\text { TLH + BSO + MUS } \\
\text { Lap sterilisation } \\
\text { +MUS }\end{array}$ & 2 & 4.16 \\
\hline
\end{tabular}

SUI repair was done under regional anaesthesia in 43 women $(89.6 \%)$ and 5 women $(10.4 \%)$ required GA due to concomitant laparoscopic procedure. The mean operative time (only SUI repair) was $10.41 \pm 2.04 \mathrm{~min}$. Five patients $(10.41 \%)$ who underwent cystocele repair for huge cystocele required urinary catheterisation for 48 hrs, of which four $(8.32 \%)$ did not require recatheterization. One patient $(2.08 \%)$ had urinary retention and was recatheterised. Even after 3 weeks of catheterisation, retention persisted and the tape was cut at its midportion, following which she was able to void and also remained continent.

Results of subjective sensation of urine control are shown in Table 4, and results of objective tests in Table 5.

The objective cure rate of the 48 patients available for follow-up was $93.75 \%$ (45 of 48). Overall, 93.75\% (45 of 48) of patients were continent, $2.08 \%$ (1 of 48) slightly incontinent and 4.16\% (2 of 48) severely incontinent. 2 patients $(4.16 \%)$ underwent repeat surgery and were cured.

Table 4: Subjective sensation of urine control of patients after Transobturator mid-urethral sling surgery.

\begin{tabular}{|lll|}
\hline Subjective status & $\begin{array}{l}\text { No. of patients } \\
\text { (n) }\end{array}$ & $\%$ \\
\hline $\begin{array}{l}\text { Complete satisfaction } \\
\text { (continent) }\end{array}$ & 45 & 93.75 \\
\hline $\begin{array}{l}\text { Improved urine } \\
\text { control } \\
\text { (slightly incontinent) }\end{array}$ & 2.08 \\
\hline $\begin{array}{l}\text { No change in urine } \\
\text { control } \\
\text { (incontinent) }\end{array}$ & 4.16 \\
\hline
\end{tabular}

Table 5: Objective tests of patients after mid-urethral sling surgery.

\begin{tabular}{|lll|}
\hline Test & $\begin{array}{l}\text { No. of patients } \\
\text { (n) }\end{array}$ & \\
\hline $\begin{array}{l}\text { Cough stress test } \\
\text { Positive }\end{array}$ & & \\
negative & 3 & 6.25 \\
\hline Pad test & 45 & 93.75 \\
\hline $1 \mathrm{~g}$ & & \\
$1-5 \mathrm{~g}$ & 45 & 93.75 \\
$>5 \mathrm{~g}$ & 1 & 2.08 \\
\hline
\end{tabular}

\section{Complications}

None of the cases suffered urethral injury or bladder perforation and none of them experienced a significant postoperative thigh pain. One patient $(1 / 48,2.08 \%)$ had postoperative urinary retention, not relieved even after 3 weeks of catheterisation. The tape was thus incised at the centre, following which she was able to void normally and also remained continent. Another patient (1/48, 2.08 $\%$ ) reported on the second postoperative month with severe dyspareunia and on examination found to have vaginal erosion of the mesh. The exposed portion of the mesh was excised and patient was symptomatically better 
and also had no recurrence. Both these patients had undergone SUI repair with Gynecare TVT-O system (inside-out approach). There was no case of urethral erosion. No major complications, notably no injury of major vessels, neurological or gastrointestinal complications were reported.

We did not observe significant between-group differences in success rate, satisfaction rate, postoperative pain, and voiding difficulty.

\section{DISCUSSION}

The treatment of stress urinary incontinence has become a minimally invasive procedure characterized by tensionfree techniques. These techniques are evolving in surgical practice from retropubic to transobturator procedures. In part, this evolution is made on the belief of increased safety with ongoing efficacy.

Recently, it has been shown that the majority of surgical procedures, particularly the minimally invasive midurethral slings, are both safe and effective treatment of female SUI. ${ }^{7}$ However, the success rates reported varied between studies, depending on whether objective or subjective outcomes had been measured. There has been a lack of consensus in the urogynecologic community about which postoperative outcome measure to use to evaluate the efficacy of surgical procedures for SUI $^{\mathbf{8}}$. In our study, we have evaluated both subjective and objective cure rates.

The objective and subjective cure rates range from $80 \%$ to $92 \%^{7}$ and seem to be similar for both techniques (outside -in and inside-out). The subjective and objective cure rate observed in our study was $93.75 \%$. One patient (Gynecare TVT-O system) remained slightly incontinent but did not undergo repeat surgery as she was satisfied with the improvement and not willing for repeat surgery. The procedure failed in two patients $(4.16 \%)$, who had to undergo repeat surgery and were subsequently cured. Failure rates and repeat surgery after mid urethral sling are reported in $7-16 \%$. $^{9}$

Coexisting urinary incontinence and pelvic organ prolapse is reported in $15-80 \%$ of patients. ${ }^{10}$ In our study, $(18.75 \%)$ patients had coexisting POP requiring surgery. ${ }^{9}$ Stress incontinence and pelvic organ prolapse share common pathophysiologic etiologies and often coexist with one another. In SUI patients with symptomatic or moderate to severe POP, concurrent POP surgery should be performed actively at the time of incontinence surgery to prevent POP exacerbation and the occurrence of dysuria. The Female Stress Urinary Incontinence Update Panel of the AUA stated that surgical procedures for SUI can be safely performed at the time of POP repair and that the sling tensioning should be performed after the completion of POP repair. ${ }^{11}$ The cure/dry rate for synthetic slings placed at the midurethra without POP repair was $84 \%$ at $\geq 48$ months and was similar to that in patients who had a concomitant POP repair ${ }^{10}$. Due to a small number of patients who underwent concomitant prolapse surgery $(n=9)$, we could not compare these two approaches.

In our study of 48 cases of mid urethral sling surgery, there were no bladder, urethral, or bowel injuries, confirming the safety of this procedure ${ }^{7}$. Studies have shown that Transobturator foramen procedures are associated with a lower incidence of bladder injuries, retropubic haematoma, and voiding difficulties than TVT, but a higher incidence of groin/thigh pain. This is in disagreement with our results, which demonstrated that no patient had significant postop groin or thigh pain.

Urinary retention requiring catheterization occurs in 2$20 \%$ of patients, although its duration is generally limited. $^{12}$ Five patients $(10.41 \%)$ in our study who underwent cystocele repair for huge cystocele were prophylactically catheterised for $48 \mathrm{hrs}$ of which only one (2.08\%) had retention not responding to prolonged catheterisation (3 weeks) but relieved on incising the mesh at its centre.

Vaginal extrusion rates of $0-6 \%$ are reported. ${ }^{13}$ In our study, we had one case $(2.08 \%)$ of vaginal erosion of the mesh with Gynecare TVT-O tape who presented on the $2^{\text {nd }}$ postoperative month with severe dyspareunia. The exposed part of the mesh was excised and the patient was relieved of her symptoms with no recurrence. In contrast in a comparative study of two versions of the transobturator tape, outside-in technique using the Obtape developed more vaginal erosion than the insideout TVT-O $(7.29$ vs $1.78 \%, p<0.05) .{ }^{14}$

De novo urgency is another bothersome symptom that some patients may suffer after suburethral tapes, reported incidence being $0-26 \%$ of patients, and is attributed to obstructive or locally irritative causes. ${ }^{15}$ Three cases $(6.25 \%)$ in our study suffered de novo urgency and all were relieved by anticholinergics.

It is not clear from our work whether the brand of the tape has played any role in these results. To reach any conclusion regarding this point, head to head comparisons should be made involving different tape brands.

\section{CONCLUSIONS}

We would like to conclude that the transobturator approach of mid urethral sling surgery is safe and effective for female SUI. Limitations of our study were small number of patients, retrospective study. In addition, reporting a case series of one surgeon has limitations with regard to generalizability. However, our results suggest comparable success and complication rates to those in the published literature. 
The bottom line is that accurate midurethral placement of the sling is required for the successful treatment of SUI. The search for the perfect treatment of SUI continues. Surgeons continue to look for the least invasive approach with optimal outcomes that also minimise the potential for adverse events peri and postoperatively.

Funding: No funding sources

Conflict of interest: None declared

Ethical approval: The study was approved by the Institutional Ethics Committee

\section{REFERENCES}

1. Serati M, Salvatore S, Uccella S, Artibani W, Novara G, Cardozo L, et al. Surgical treatment for female stress urinary incontinence: what is the gold-standard procedure? Int Urogynecol J Pelvic Floor Dysfunct. 2009;20:619-21.

2. Margareta N, Ann L, Othon L. The impact of female urinary incontinence and urgency on quality of life and partner relationship. Neurourol Urodyn. 2009;28(8):976-81.

3. Petros PE, Ulmsten UI. An integral theory of female urinary incontinence. Experimental and clinical considerations. Acta Obstet Gynecol Scand Suppl. 1990;153:7-31.

4. Costantini E, Lazzeri, M. Porena. Managing Complications after Midurethral Sling for Stress Urinary Incontinence. European Urology. 2007;5:232-40.

5. Delorme E. Transobturator urethral suspension; mini invasive procedure in the treatment of stress incontinence in women. Prog Urol. 2001;11:130613.

6. De Leval J. Novel surgical technique for the treatment of female stress urinary incontinence: transobturator vaginal tape inside-out. Eur Urol. 2003;44:724-30.

7. Bassem S, Mansour A, Ahmed S. El-Hefnawy, Adel $\mathrm{N}$ and Albair A. Minimum 2-year follow-up of mid- urethral slings, effect on quality of life, incontinence impact and sexual function. Int Urol $\mathrm{J}$. 2010;21:1485-90.

8. Haliloglu B, Diaa E, Rizk E. Subjective versus objective measurement of surgical outcomes of treatment of female stress urinary incontinence: it is not just black and white. Int Urogynecol J. 2010;21:761-62.

9. Rui O, Francisco B, Pedro S, Alexandre R, Carlos S

10. Bai SW, Jeon MJ, Kim JY. Relationship between stress urinary incontinence and pelvic organ prolapse. Int Urogynecol J Pelvic Floor Dysfunct. 2002;13:256.

11. Dmochowski RR, Blaivas JM, Gormley EA. Update of AUA Guideline on the Surgical Management of Female Stress Urinary Incontinence. Female Stress Urinary Incontinence Update Panel of the American Urological Association Education and Research, Inc. J Urol. 2010;183:1906-14.

12. Levin I. Surgical complications and medium-term outcome results of tension-free vaginal tape: a prospective study of 313 consecutive patients. Neurourol Urodyn 2004;23:7-9.

13. Rezapour M, Ulmsten. Tension-free vaginal tape (TVT) in women with mixed urinary incontinence - a long-term follow-up. Int Urogynecol J Pelvic Floor Dysfunct 12 (Suppl 2). 2001;S15-S18.

14. Deval B. Objective and subjective cure rates after trans-obturator tape (OBTAPE) treatment of female urinary incontinence. Eur Urol. 2006;49:373-7.

15. Bullock TL. Advances in female stress urinary incontinence: mid-urethral slings. BJU Int. 2006;98(Suppl 1):32-40.

Cite this article as: Bettaiah R, Saraogi R, Reddy C Transobturator mid urethral sling surgery for stress urinary incontinence: our experience. Int J Reprod Contracept Obstet Gynecol 2015;4:1831-5. 